\title{
White Matter Injury and Structural Anomalies in Infants with Prenatal Opioid Exposure
}

\author{
(D) S.L. Merhar, (D) N.A. Parikh, (D) A. Braimah, (D)B.B. Poindexter, (D). Tkach, and (D) B. Kline-Fath
}

\begin{abstract}
SUMMARY: Previous studies have not found structural injury or brain malformations in infants and children with prenatal opioid exposure. As part of an ongoing study evaluating neuroimaging in infants with prenatal opioid exposure, we reviewed structural brain MR imaging in 20 term infants with prenatal opioid exposure and 20 term controls at 4-8 weeks of age. We found that 8 of the 20 opioid-exposed infants had punctate white matter lesions or white matter signal abnormality on structural MR imaging, and 2 of the opioid-exposed infants had a septopreoptic fusion anomaly. No controls had white matter injury or structural malformations. Our findings underscore the importance of clinical neurodevelopmental follow-up and the need for more comprehensive imaging and long-term outcomes research following prenatal opioid exposure.
\end{abstract}

D ue to the ongoing opioid epidemic, $>40,000$ infants are now born exposed to opioids each year in the United States. The few previous studies evaluating structural neuroimaging in infants with prenatal opioid exposure have found no increase in the incidence of macrostructural injury or malformations. ${ }^{1,2}$ More recent studies have shown decreased head circumference, ${ }^{3}$ decreased brain volumes, ${ }^{4,5}$ and altered white matter microstructure $^{6}$ in infants with prenatal opioid exposure compared with controls. Prior studies may have been confounded by coexposures because most opioid-exposed infants are also exposed to tobacco in utero, ${ }^{7}$ and a large proportion are also exposed to hepatitis C. ${ }^{8}$ Prenatal tobacco exposure is also associated with decreased head circumference ${ }^{9}$ and brain volumes. ${ }^{10-12}$ There are no reports of neuroimaging after prenatal hepatitis $\mathrm{C}$ exposure in infants or children, but adults with active hepatitis $\mathrm{C}$ infection are known to have white matter changes. ${ }^{13}$ As part of a larger prospective study, we acquired structural brain MRIs in infants with prenatal opioid exposure and controls. Here we report our findings of white matter injury and congenital structural malformations in infants with prenatal opioid exposure, all of whom also

Received July 1, 2019; accepted after revision September 3.

From the Perinatal Institute, Division of Neonatology (S.L.M., N.A.P., B.B.P.), Pediatric Neuroimaging Research Consortium (A.B.), and Department of Radiology (J.T., B.K.-F.), Cincinnati Children's Hospital Medical Center, Cincinnati, Ohio; and Department of Pediatrics (S.L.M., N.A.P., B.B.P.), University of Cincinnati College of Medicine, Cincinnati, Ohio.

Dr Merhar was supported by National Institutes of Health KL2 TR1426.

Please address correspondence to Stephanie L. Merhar, MD, MS, Cincinnati Children's Hospital, Division of Neonatology, 3333 Burnet Ave ML 7009, Cincinnati OH 45229; e-mail: Stephanie.merhar@cchmc.org

- Indicates open access to non-subscribers at www.ajnr.org

http://dx.doi.org/10.3174/ajnr.A6282 had tobacco exposure and all of whom except one had hepatitis $\mathrm{C}$ exposure.

\section{MATERIALS AND METHODS}

As part of an ongoing prospective cohort study on functional brain connectivity in infants with opioid exposure, we acquired structural MR imaging in 4- to 8-week-old infants with confirmed prenatal opioid exposure and unexposed healthy term controls. Inclusion criteria for the opioid-exposed group included infants $\geq 37$ weeks' gestation with known exposure to maternal buprenorphine or methadone during pregnancy and no known prenatal alcohol exposure. Inclusion criteria for controls were infants of $\geq 37$ weeks' gestation with no opioid, alcohol, or illicit drug exposure during pregnancy confirmed by maternal urine toxicology screen and maternal history. Exclusion criteria for both groups included a 5-minute Apgar score of $<7$, any need for positive pressure ventilation at any time after birth, head trauma, and known chromosomal or congenital anomalies potentially affecting the central nervous system. Opioid-exposed infants were recruited from surrounding birth hospitals and the Cincinnati Children's opioid-exposed follow-up clinic. Controls were recruited from surrounding birth hospitals, flyers in surrounding pediatric offices, and e-mails sent to all hospital employees.

The study was approved by the Cincinnati Children's Hospital Medical Center Institutional Review Board, and written informed consent was obtained from parents/guardians. Images were acquired on a 3T Ingenia scanner (Philips Healthcare, Best, the Netherlands) with a 32-channel head coil during natural sleep using the feed-and-swaddle method. MR imaging included a 


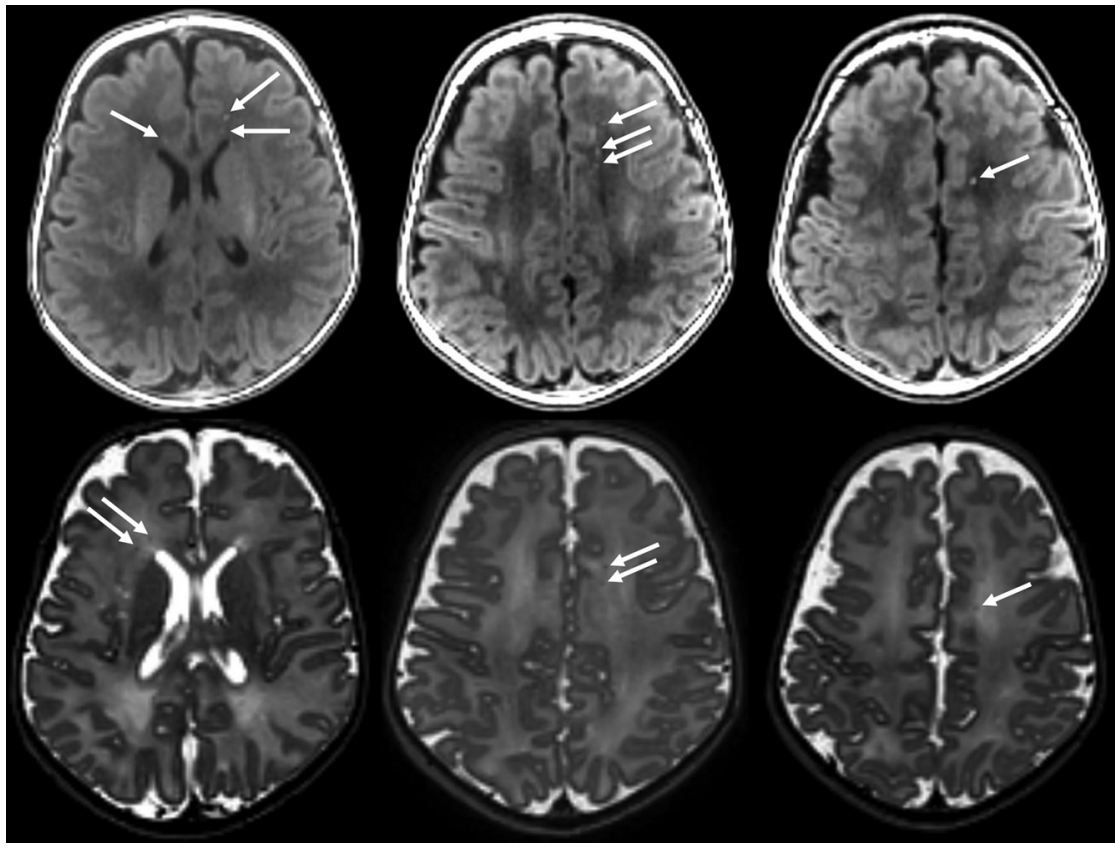

FIG 1. Example of punctate white matter injury seen in an infant with prenatal opioid exposure. Arrows show punctate white matter lesions. Upper row, T1-weighted images. Lower row, T2weighted images.

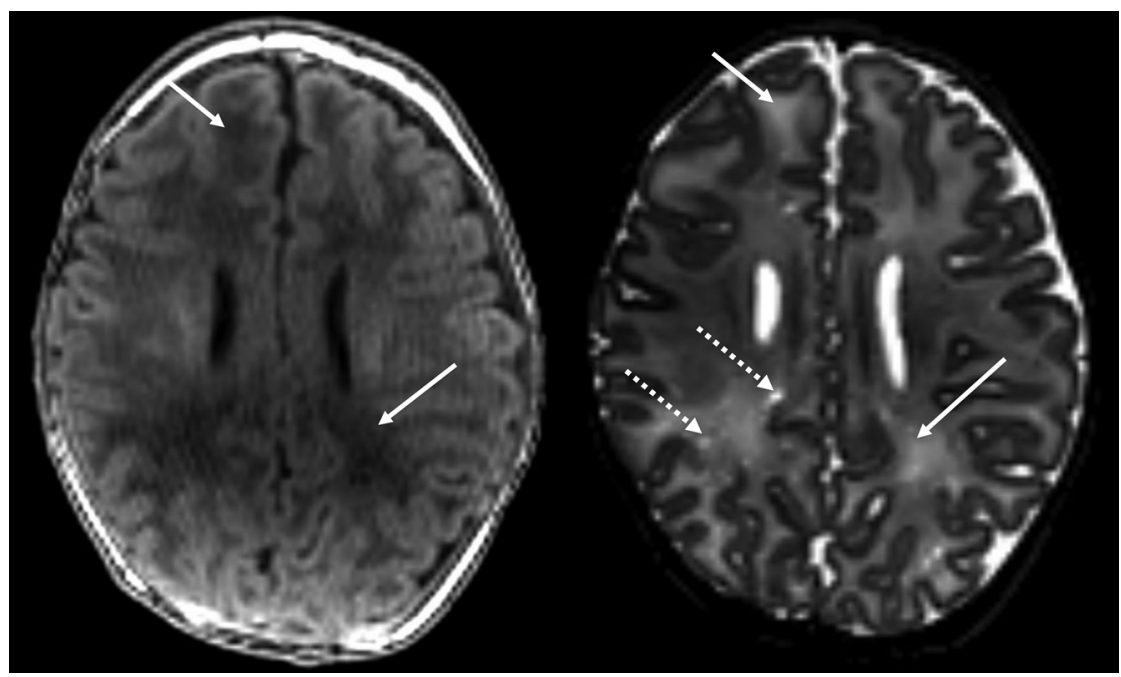

FIG 2. Example of diffuse white matter injury in infants with prenatal opioid exposure. Solid arrows denote abnormal $\mathrm{T} 1$ and $\mathrm{T} 2$ prolongation (which is bilateral but only denoted on the right). Dotted arrow demonstrates an example of perivascular space enlargement. Left, T1weighted image. Right, T2-weighted image.

sagittal 3D T1-weighted gradient-echo sequence (voxel size $=$ $1 \times 1 \times 1 \mathrm{~mm}$; scan time 3 minutes 6 seconds), an axial T2weighted fast spin-echo sequence (voxel size $=1 \times 1.11 \times$ $1 \mathrm{~mm}$; scan time 3 minutes 19 seconds), an axial 6-direction single-shot echo-planar DWI sequence (b-value $=800$; voxel size $=2 \times 2 \times 2 \mathrm{~mm}$; scan time $=1: 47$ minutes $)$, and an axial $3 \mathrm{D}$-SWI sequence (voxel size $=0.6 \times 0.6 \times 2 \mathrm{~mm}$; scan time 4 minutes 3 seconds).

We reviewed electronic medical records from the infant's birth hospitalization for information including gestational age, birth weight/length/head circumference, sex, Apgar scores, results of maternal urine toxicology screen (done universally at the time of delivery at our surrounding birth hospitals), maternal medications and medical problems during pregnancy, maternal hepatitis C status, and length of hospital stay. Additional information reviewed for infants with opioid exposure included the results of neonate toxicology screen, the need for and type of treatment for neonatal abstinence syndrome, and the length of opioid treatment for neonatal abstinence syndrome, if necessary. At the time of the MR imaging visit, mothers filled out a questionnaire with selfreported information about their use of prescription medications, illicit drugs, alcohol, and tobacco during pregnancy.

MR images were reviewed by a single pediatric neuroradiologist blinded to clinical history. Initially a clinical read was reported to rule out structural injury, and then MRIs were scored in detail using a scoring system based on Kidokoro et al, ${ }^{14}$ which included white matter abnormalities (cystic white matter lesions, focal signal abnormality, corpus callosum thinning, dilated lateral ventricles), cortical gray matter abnormalities, and deep gray matter and cerebellar abnormalities. The MR imaging scores were based on all 4 sequences (T1, T2, DWI, and SWI).

\section{RESULTS}

We included 40 infants, 20 with prenatal opioid exposure and 20 controls. Eight of the 20 infants (40\%) with prenatal opioid exposure had punctate foci of white matter injury or more diffuse white matter injury seen on the initial clinical read by the radiologist. Two of the opioid-exposed infants were also incidentally found to have septopreoptic fusion, a very mild form of holoprosencephaly. One of these 2 infants also had punctate white matter lesions. An example of the punctate white matter injury is shown in Fig 1. An example of the diffuse white matter injury is shown in Fig 2. No white matter injury or congenital structural malformations were observed in any of the control infants. One control infant had mildly enlarged extra-axial fluid spaces, one had a borderline small cerebellar vermis, and one had germinolytic cysts at the caudothalamic grooves bilaterally. One infant in each group (opioid-exposed and controls) had 
Characteristics of prenatal opioid-exposed and healthy term control study cohorts

\begin{tabular}{|c|c|c|c|}
\hline & WMI $(n=8)$ & No WMI $(n=12)$ & Control $(n=20)$ \\
\hline Gestational age at birth (weeks) & $38.9(0.74)$ & $38.9(0.93)$ & $39.0(0.80)$ \\
\hline Day of life at scan ${ }^{a}$ & $40.6(9.5)$ & $43.0(8.5)$ & $39.3(6.1)$ \\
\hline Birth weight $(g)^{a}$ & 3172 (302) & $2982(321)$ & $3201(460)$ \\
\hline Birth head circumference $(\mathrm{cm})^{\mathrm{a}}$ & $34.4(1.2)$ & $33.9(1.4)$ & $34.0(1.5)$ \\
\hline Mom methadone ${ }^{b}$ & $4(50 \%)$ & $4(33 \%)$ & $0(0 \%)$ \\
\hline Mom buprenorphine ${ }^{b}$ & $4(50 \%)$ & $8(67 \%)$ & $0(0 \%)$ \\
\hline Mom street drugs ${ }^{b}$ & $3(38 \%)$ & $3(25 \%)$ & $0(0 \%)$ \\
\hline Mom alcohol ${ }^{b}$ & $0(0 \%)$ & $0(0 \%)$ & $0(0 \%)$ \\
\hline Mom smoking ${ }^{b}$ & $8(100 \%)$ & $11(92 \%)$ & $0(0 \%)$ \\
\hline Mom hepatitis $C^{b}$ & $7(88 \%)$ & $9(75 \%)$ & $0(0 \%)$ \\
\hline Baby treated for $\mathrm{NAS}^{b}$ & $5(63 \%)$ & $7(58 \%)$ & $0(0 \%)$ \\
\hline
\end{tabular}

Note:-NAS indicates neonatal abstinence syndrome; WMI, WM injury; Mom, mother.

${ }^{a}$ Values are mean (SD)

${ }^{\mathrm{b}}$ Values are No. (\%).

a small cerebellar germinal matrix hemorrhage. No other infants in either group had cortical gray matter, deep gray matter, or cerebellar abnormalities. Demographics and exposures for the 3 groups (prenatal opioid exposure with WM injury, prenatal opioid exposure without WM injury, and unexposed controls) are shown in the Table. As shown in the Table, all 8 infants with white matter injury also had tobacco exposure and 7 of the 8 also had hepatitis $C$ exposure. No infant in any group was exposed to alcohol prenatally per parental report.

\section{DISCUSSION}

White matter injury is described most commonly in infants born preterm, but it can also occur in full-term infants who sustain in utero insults during a susceptible period of white matter development. ${ }^{15}$ Both diffuse and punctate white matter lesions are thought to be related to the selective vulnerability of preoligodendrocytes. ${ }^{15}$ Punctate white matter lesions are small patches of increased signal intensity seen on T1-weighted imaging corresponding to areas of either small necroses, glial scars, or microhemorrhage. ${ }^{16}$ Punctate white matter lesions have also been reported in term and late-preterm infants with congenital heart disease, hypoxic-ischemic encephalopathy, and genetic disorders, and following neonatal surgery. ${ }^{17}$ In term infants with congenital heart disease, punctate white matter lesions are thought to be due to abnormal brain maturation due to disrupted blood flow and hypoxia from the cardiac lesion, ${ }^{18}$ leading to a delay in the maturation of preoligodendrocytes. ${ }^{19}$ Neurodevelopmental sequelae of punctate white matter lesions are variable, with some preterm infants with small isolated lesions (as in our cohort) reported as healthy, while others with more extensive lesion burden displaying motor and cognitive delays. ${ }^{20,21}$ Diffuse non-necrotic white matter injury is also commonly seen in preterm infants and also reflects disruption of the normal maturation of preoligodendrocytes. ${ }^{15,16,22}$ Outcomes after this diffuse mild injury are also variable. Studies that used qualitative diagnosis of diffuse signal abnormalities report normal developmental outcomes, ${ }^{23-25}$ while studies that quantify it objectively or follow children with extensive hyperintensity report later cognitive and language delays. ${ }^{26,27}$

In our cohort of infants with prenatal opioid exposure, the etiology of the white matter injury is unclear. All 8 mothers were on medication-assisted therapy (in methadone treatment programs and 4 in buprenorphine treatment programs) throughout pregnancy, and 3 mothers had used street drugs early in pregnancy per maternal report and review of maternal urine toxicology. All of the mothers smoked during this pregnancy, and all except 1 of the mothers were positive for hepatitis C. WM injury has not been previously re-ported in the literature in association with prenatal opioid, tobacco, or hepatitis $\mathrm{C}$ exposure.

Two of the infants with prenatal opioid exposure were also incidentally found to have a septopreoptic fusion anomaly. This anomaly has been described in a single case series in the literature as the mildest form of holoprosencephaly, in which the septal and preoptic regions are fused and the rest of the brain undergoes normal cleavage. $^{28}$ Cleavage of the prosencephalon normally occurs between days 18 and 28 of gestation. ${ }^{29}$ Holoprosencephaly has been associated with various genes and also environmental factors such as maternal diabetes, maternal alcohol use, and maternal infections. ${ }^{30}$ One of the 2 infants with this malformation had a mother with "borderline gestational diabetes" during her pregnancy, but the other had no record of diabetes in the maternal or infant chart. We could not find any literature describing an association between prenatal opioid exposure and holoprosencephaly in animal models. This finding in 2 of our 20 patients could very well be coincidental because there are no other reported cases of this association in either the human or animal literature.

The few studies evaluating structural brain MR imaging in infants with prenatal opioid exposure have concluded that there is no increase in macrostructural injury compared with controls. ${ }^{1,2}$ One of these studies used a 1.5T MR imaging scanner with thicker slices $(4 \mathrm{~mm})$, which could explain the lack of findings, ${ }^{2}$ but the other used a $3 \mathrm{~T}$ scanner with 1 -mm slices, ${ }^{1}$ similar to our protocol. Studies using more advanced MR imaging techniques have documented smaller brain volumes, ${ }^{4,5,31,32}$ altered white matter microstructure, ${ }^{6,33,34}$ and decreased cortical surface area and thickness ${ }^{5}$ in opioidexposed infants and children compared with controls. None of these studies controlled for maternal smoking, and many included mothers with polysubstance use during pregnancy. However, animal studies have consistently shown the effects of prenatal methadone and buprenorphine on neurotransmitter biosynthesis, ${ }^{35,36}$ neurogenesis, ${ }^{37}$ and white matter development, ${ }^{38,39}$ providing evidence that opioids themselves likely affect brain development.

Overt brain injury has not been reported in infants exposed to tobacco during pregnancy. However, studies have shown an association between prenatal tobacco exposure and smaller brain volumes $^{10}$ and decreased cortical thickness. ${ }^{10,12,40}$ There is no information in the literature about perinatal hepatitis $\mathrm{C}$ exposure and the developing brain, especially in the large majority of infants who are exposed to the virus but do not acquire the infection. However, hepatitis $\mathrm{C}$ is known to invade the central nervous 
system and lead to neurotoxicity, including altered white matter integrity in adults. ${ }^{13}$

\section{CONCLUSIONS}

We found that 8 of 20 infants with prenatal opioid exposure, all of whom also had coexposure to tobacco and all except 1 who had exposure to hepatitis $\mathrm{C}$, had mild white matter injury seen on structural MR imaging at 4-8 weeks of age, and 2 of the 20 opioid-exposed infants had a septopreoptic fusion anomaly. Our study was limited by small sample size, and further studies must explore these associations in a much larger population.

Disclosures: Stephanie L. Merhar-RELATED: Grant: National Institutes of Health, Comments: KL2 TR 1426*; UNRELATED: Employment: Children's Hospital Medical Center (Cincinnati). Brenda B. Poindexter-RELATED: Grant: National Institutes of Health, Comments: National Institutes of Health/Eunice Kennedy Shriver National Institute of Child Health and Human Development UGl HD027853-27S1 Clinical Research Investigator Supplement Award*; UNRELATED: Employment: Cincinnati Children's Hospital. *Money paid to institution.

\section{REFERENCES}

1. Sirnes E, Elgen IB, Chong WK, et al. Cerebral magnetic resonance imaging in children with prenatal drug exposure. Clin Pediatr (Phila) 2017;56:326-32 CrossRef Medline

2. Kahila H, Kivitie-Kallio S, Halmesmäki E, et al. Brain magnetic resonance imaging of infants exposed prenatally to buprenorphine. Acta Radiol 2007;48:228-31 CrossRef Medline

3. Towers CV, Hyatt BW, Visconti KC, et al. Neonatal head circumference in newborns with neonatal abstinence syndrome. Pediatrics 2019;143:e20180541 CrossRef Medline

4. Sirnes E, Oltedal L, Bartsch H, et al. Brain morphology in schoolaged children with prenatal opioid exposure: a structural MRI study. Early Hum Dev 2017;106-107:33-39 CrossRef Medline

5. Nygaard E, Slinning K, Moe V, et al. Neuroanatomical characteristics of youths with prenatal opioid and poly-drug exposure. Neurotoxicol Teratol 2018;68:13-26 CrossRef Medline

6. Monnelly VJ, Anblagan D, Quigley A, et al. Prenatal methadone exposure is associated with altered neonatal brain development. Neuroimage Clin 2018;18:9-14 CrossRef Medline

7. Chisolm MS, Fitzsimons H, Leoutsakos JM, et al. A comparison of cigarette smoking profiles in opioid-dependent pregnant patients receiving methadone or buprenorphine. Nicotine Tob Res 2013;15: 1297-1304 CrossRef Medline

8. Epstein RL, Sabharwal V, Wachman EM, et al. Perinatal transmission of hepatitis $\mathrm{C}$ virus: defining the cascade of care. J Pediatr 2018;203:34-40.e31 CrossRef Medline

9. Ekblad M, Korkeila J, Lehtonen L. Smoking during pregnancy affects foetal brain development. Acta Paediatr 2015;104:12-18 CrossRef Medline

10. El Marroun H, Schmidt MN, Franken IH, et al. Prenatal tobacco exposure and brain morphology: a prospective study in young children. Neuropsychopharmacol 2014;39:792-800 CrossRef Medline

11. Roza SJ, Verburg BO, Jaddoe VW, et al. Effects of maternal smoking in pregnancy on prenatal brain development: the Generation $R$ Study. Eur J Neurosci 2007;25:611-17 CrossRef Medline

12. Anblagan D, Jones NW, Costigan C, et al. Maternal smoking during pregnancy and fetal organ growth: a magnetic resonance imaging study. PLoS One 2013;8:e67223 CrossRef Medline

13. Bladowska J, Zimny A, Knysz B, et al. Evaluation of early cerebral metabolic, perfusion and microstructural changes in $\mathrm{HCV}$-positive patients: a pilot study. J Hepatol 2013;59:651-57 CrossRef Medline

14. Kidokoro H, Neil JJ, Inder TE. New MR imaging assessment tool to define brain abnormalities in very preterm infants at term. AJNR Am J Neuroradiol 2013;34:2208-14 CrossRef Medline

15. Back SA. White matter injury in the preterm infant: pathology and mechanisms. Acta Neuropathol 2017;134:331-49 CrossRef Medline
16. Volpe JJ. Confusions in nomenclature: "periventricular leukomalacia" and "white matter injury"-identical, distinct, or overlapping? Pediatr Neurol 2017;73:3-6 CrossRef Medline

17. Hayman M, van Wezel-Meijler G, van Straaten $H$, et al. Punctate white-matter lesions in the full-term newborn: underlying aetiology and outcome. Eur J Paediatr Neurol 2019;23:280-87 CrossRef Medline

18. Marelli A, Miller SP, Marino BS, et al. Brain in congenital heart disease across the lifespan: the cumulative burden of injury. Circulation 2016;133:1951-62 CrossRef Medline

19. Guo T, Chau V, Peyvandi S, et al. White matter injury in term neonates with congenital heart diseases: topology and comparison with preterm newborns. Neuroimage 2019;185:742-49 CrossRef Medline

20. Cornette LG, Tanner SF, Ramenghi LA, et al. Magnetic resonance imaging of the infant brain: anatomical characteristics and clinical significance of punctate lesions. Arch Dis Child Fetal Neonatal Ed 2002;86:F171-77 CrossRef Medline

21. Tusor N, Benders MJ, Counsell SJ, et al. Punctate white matter lesions associated with altered brain development and adverse motor outcome in preterm infants. Sci Rep 2017;7:13250 CrossRef Medline

22. Parikh NA, Pierson CR, Rusin JA. Neuropathology associated with diffuse excessive high signal intensity abnormalities on magnetic resonance imaging in very preterm infants. Pediatr Neurol 2016;65:78-85 CrossRef Medline

23. de Bruïne FT, van den Berg-Huysmans AA, Leijser LM, et al. Clinical implications of MR imaging findings in the white matter in very preterm infants: a 2-year follow-up study. Radiology 2011;261:899906 CrossRef Medline

24. Jeon TY, Kim JH, Yoo SY, et al. Neurodevelopmental outcomes in preterm infants: comparison of infants with and without diffuse excessive high signal intensity on MR images at near-term-equivalent age. Radiology 2012;263:518-26 CrossRef Medline

25. Broström L, Bolk J, Padilla N, et al. Clinical implications of diffuse excessive high signal intensity (DEHSI) on neonatal MRI in school age children born extremely preterm. PLoS One 2016;11:e149578 CrossRef Medline

26. Parikh NA, He L, Bonfante-Mejia E, et al. Automatically quantified diffuse excessive high signal intensity on MRI predicts cognitive development in preterm infants. Pediatr Neurol 2013;49:424-30 CrossRef Medline

27. Mürner-Lavanchy IM, Kidokoro H, Thompson DK, et al. Thirteenyear outcomes in very preterm children associated with diffuse excessive high signal intensity on neonatal magnetic resonance imaging. J Pediatr 2019;206:66-71.e61 CrossRef Medline

28. Hahn JS, Barnes PD, Clegg NJ, et al. Septopreoptic holoprosencephaly: a mild subtype associated with midline craniofacial anomalies. AJNR Am J Neuroradiol 2010;31:1596-1601 CrossRef Medline

29. Dubourg C, Bendavid C, Pasquier L, et al. Holoprosencephaly. Orphanet J Rare Dis 2007;2:8 CrossRef Medline

30. Johnson CY, Rasmussen SA. Non-genetic risk factors for holoprosencephaly. Am J Med Genet C Semin Med Genet 2010;154C:73-85 CrossRef Medline

31. Yuan Q, Rubic M, Seah J, et al. Do maternal opioids reduce neonatal regional brain volumes? A pilot study. J Perinatol 2014;34:90913 CrossRef Medline

32. Walhovd KB, Moe V, Slinning K, et al. Volumetric cerebral characteristics of children exposed to opiates and other substances in utero. Neuroimage 2007;36:1331-44 CrossRef Medline

33. Walhovd KB, Watts R, Amlien I, et al. Neural tract development of infants born to methadone-maintained mothers. Pediatr Neurol 2012;47:1-6 CrossRef Medline

34. Walhovd KB, Westlye LT, Moe V, et al. White matter characteristics and cognition in prenatally opiate- and polysubstance-exposed children: a diffusion tensor imaging study. AJNR Am J Neuroradiol 2010;31:894-900 CrossRef Medline 
35. Robinson SE, Maher JR, Wallace MJ, et al. Perinatal methadone exposure affects dopamine, norepinephrine, and serotonin in the weanling rat. Neurotoxicol Teratol 1997;19:295-303 CrossRef Medline

36. $\mathrm{Wu} \mathrm{VW}, \mathrm{Mo} \mathrm{Q}$, Yabe $\mathrm{T}$, et al. Perinatal opioids reduce striatal nerve growth factor content in rat striatum. Eur J Pharmacol 2001; 414:211-14 CrossRef Medline

37. Wu CC, Hung CJ, Shen $\mathrm{CH}$, et al. Prenatal buprenorphine exposure decreases neurogenesis in rats. Toxicol Lett 2014;225:92-101 CrossRef Medline
38. Vestal-Laborde AA, Eschenroeder AC, Bigbee JW, et al. The opioid system and brain development: effects of methadone on the oligodendrocyte lineage and the early stages of myelination. Dev Neurosci 2014;36:409-21 CrossRef Medline

39. Sanchez ES, Bigbee JW, Fobbs W, et al. Opioid addiction and pregnancy: perinatal exposure to buprenorphine affects myelination in the developing brain. Glia 2008;56:1017-27 CrossRef Medline

40. Toro R, Leonard G, Lerner JV, et al. Prenatal exposure to maternal cigarette smoking and the adolescent cerebral cortex. Neuropsychopharmacol 2008;33:1019-27 CrossRef Medline 